\title{
Pattern of hospital admission before and following the Mental Health Act 1983
}

\author{
S. K. Durani, Clinical Medical Officer, Herts \& Essex General Hospital, Bishop's \\ Stortford, Herts and R. FORD, Research Registrar, Kings College, London
}

The Mental Health Act brought a number of signficant changes to psychiatric practice. Among the most important were changes in the process of compulsory admissions. Other notable alterations have been a change in the definition of the nearest relative; a reduction in duration of treatment section by a half; a right to appeal against their detention by all patients; the observation section becoming an assessment and treatment section; the introduction of nurses holding power; the removal of age limits for admission of patients with psychopathic disorder and mental impairment, and the introduction of the treatability clause. These and other important differences could be expected to interact with social work and psychiatric practice to influence the number of compulsory admissions. Previous correspondence has examined this question, to which we add our findings.

The process of admission to hospital is a complex one with numerous interacting variables, which include the patient, family, social worker, general practitioner, psychiatrist and nursing staff, and the availability of an approved doctor. Any or all of these could mean the difference between informal and compulsory admission.

As previous authors have done, we have examined the admission figures to a local hospital for the years immediately preceding and following the introduction of the MHA 1983. Moorhaven Hospital is a large traditional hospital with a catchment area population of $3,250,000$ from south west Devon, which includes the city of Plymouth and small towns and villages in the surrounding countryside. The population is heterogeneous, with large working and middle class groups and a very small number of ethnic minorities. The whole range of acute and general psychiatric admissions are accepted.

Our findings are shown in Table I and II. Several interesting factors are noticeable from these figures. Firstly, the number of informal admissions was $17 \%$ higher in the three year period following the new act than in the three years immediately preceding it, although the number of compulsory admissions is almost unchanged. Secondly, there has been an increase in the use of the 28 day section together with a large increase in the use of the treatment section, both concomitant with a large decrease in the use of the emergency admission section.

We have also given figures based on the age groups, which show there has been no consistent change in the use of compulsory admissions for the over 60 year age group.

TABLE I

Admissions to Moorhaven Hospital

\begin{tabular}{|c|c|c|c|}
\hline Section & $1980 / 81$ & $1981 / 82$ & $1982 / 3$ \\
\hline $\begin{array}{l}28 \text { days } 25(2) \\
6 \text { months } 26(3) \\
\text { Emergency } 29(4) \\
\text { Other }\end{array}$ & $\begin{array}{c}53(54 \%) \\
4(4 \%) \\
40(41 \%) \\
1(1 \%)\end{array}$ & $\begin{array}{c}41(55 \%) \\
2(3 \%) \\
28(37 \%) \\
4(5 \%)\end{array}$ & $\begin{array}{c}27(40 \%) \\
4(6 \%) \\
30(44 \%) \\
7(10 \%)\end{array}$ \\
\hline Total & $98(8 \%)$ & $75(7 \%)$ & $68(7 \%)$ \\
\hline \multirow[t]{2}{*}{ Informal } & $1083(92 \%)$ & $1002(93 \%)$ & $950(93 \%)$ \\
\hline & $1983 / 84$ & $1984 / 85$ & $1985 / 86$ \\
\hline $\begin{array}{l}28 \text { days } 2(25) \\
6 \text { months } 3(26) \\
\text { Emergency } 4(29) \\
\text { Other }\end{array}$ & $\begin{array}{l}56(74 \%) \\
7(9 \%) \\
5(7 \%) \\
8(10 \%)\end{array}$ & $\begin{array}{c}55(70 \%) \\
13(16 \%) \\
8(10 \%) \\
3(4 \%)\end{array}$ & $\begin{array}{c}54(67 \%) \\
15(18 \%) \\
7(8 \%) \\
5(6 \%)\end{array}$ \\
\hline Total & $76(6 \%)$ & $79(6 \%)$ & $81(7 \%)$ \\
\hline Informal & $1180(94 \%)$ & $1241(94 \%)$ & $1139(93 \%)$ \\
\hline
\end{tabular}

TABLE II

Age groups

\begin{tabular}{llll}
\hline Age group & $1980 / 81$ & $1981 / 82$ & $1982 / 83$ \\
\hline $0-60$ years & $77(79 \%)$ & $63(84 \%)$ & $50(74 \%)$ \\
$60+$ years & $21(21 \%)$ & $12(16 \%)$ & $18(20 \%)$ \\
\hline & $1983 / 84$ & $1984 / 85$ & $1985 / 86$ \\
\cline { 2 - 4 } & $51(77 \%)$ & $54(68 \%)$ & $58(72 \%)$ \\
$0-60$ years & $25(23 \%)$ & $25(32 \%)$ & $23(28 \%)$ \\
\hline
\end{tabular}


Our figures are similar to those of Sackett (1987) at Coney Hill Hospital both before and after the introduction of the MHA 1983. The pattern of compulsory admission after the new act closely resembles that of Darvill \& White (1987) in Bristol. Winterton $\&$ Barraclough (1985) found an increase in the use of Section $25 / 2$ but a reduction in the use of the treatment section. Our finding of an increase in the number of informal admissions is unexpected and is more surprising, when it is noted that the number of compulsory admissions is virtually unchanged. It seems that other hospitals have experienced similar phenomena, if their figures are studied carefully. Our figure of a $17 \%$ increase can be compared with a $12 \%$ increase for the corresponding three year admission total to Coney Hill Hospital. The figures for Barrow Hill Hospital show a $21 \%$ increase in informal admission for the corresponding three year period. Similarly there is a $12 \%$ increase for the Southampton hospital. The only variable here could be the introduction of the new Mental Health Act to account for this interesting phenomenon. It seems that these findings are not coincidental but show a real association between the MHA 1983 and an increased rate of informal admissions.

It may be that the threshold for admitting patients to hospitals has been reduced in some ways. This would be consistent with an unchanged or reduced number of compulsory admissions, since the extra cases would then be expected to come from the milder end of the spectrum of mental illness. Another possible explanation is that our sensitivity to detect mental illness has increased or that we are simply being cautious, perhaps with increased awareness of the legal implications of our practice.
The reason for the greatly increased use of the treatment sections in our figures may have been partly due to the reduction in the duration of the section from 12 to 6 months; however, this cannot be the whole explanation, as from our experience it seems rare to use two or more consecutive treatment sections. Also, the use of treatment sections was found to be unchanged in Bristol and reduced in Southampton.

Taking the results from the four hospitals, it would appear that some of the changes which have occurred are consistent with the intended spirit of the 1983 MHA. Thus it seems that the emergency admission sections may have been abused somewhat under the 1959 MHA and that its use only declined when the new act was introduced. The provisions for treatment under Section 2 seem to have been a positive move in helping to reduce unnecessary emergency admissions, as is the appropriate increase in the use of treatment sections.

The definite trend of an increase in informal admissions remain unexplained and deserves further study.

\section{References}

Darvill, D. \& White, A. (1987) Effects of the Mental Health Act 1983. Bulletin of the Royal College of Psychiatrists, 11, 136.

SACKETT, K. (1987) Effects of the Mental Health Act on compulsory admissions. Bulletin of the Royal College of Psychiatrists, 11, 314-316.

WINTERTON, M. J. \& BARRACLOUGH, B. M. (1985) Effects of the 1983 Mental Health Act. Lancet, ii, 1426. 